Brit. J. prev. soc. Med. (1967), 21, 163-169

\title{
ASSESSMENT OF HABITUAL PHYSICAL ACTIVITY APART FROM OCCUPATION
}

\author{
BY \\ S. YASIN, M. R. ALDERSON, J. W. MARR, D. C. PATTISON, AND J. N. MORRIS \\ From the Medical Research Council Social Medicine Research Unit, The London Hospital
}

The hypothesis that habitual physical activity protects against coronary (ischaemic) heart disease is derived from statistical comparisons which show that incidence, prevalence, and mortality rates vary inversely with the average levels of exercise involved in different occupations (Morris, Heady, Raffle, Roberts, and Parks, 1953). Similar findings were subsequently made in a variety of studies of occupational groups in several countries (Brown, Davidson, McKeown, and Whitfield, 1957; Morris and Crawford, 1958; Zukel, Lewis, Enterline, Painter, Ralston, Fawcett, Meredith, and Peterson, 1959; Breslow and Buell, 1960; Brunner and Manelis, 1960; Alexsandrow, 1962; Myasnikov, 1962; Taylor, Klepetar, Keys, Parlin, Blackburn, and Puchner, 1962; Kahn, 1963; Higgins, Cochrane, and Thomas, 1963; Keys and 13 others, 1966; Skinner, Benson, McDonough, and Hames, 1966). In a California study, however, there was no such correlation (Chapman and Massey, 1964). Such findings are of diminishing interest for public health, because occupational activity levels are decreasing with technological advance. It is important now to determine whether exercise apart from work, and particularly in leisure, has any protective value against coronary heart disease (Morris, 1967). Dawber, Kannel, and Friedman (1966), using a Physical Activity Index which combines occupational and leisure activity, report less coronary heart disease among the more active men. The preliminary findings in a New York case-control study (Frank, Weinblatt, Shapiro, and Sager, 1966) show a lower incidence and mortality from first mycardial infarction in men classed as most active by a combination again of job-connected and off-job activity.

One way to investigate this problem would be to study men in the same sedentary occupation, to grade them according to their leisure-activity levels, and then to observe prospectively whether incidence rates are less in those graded as physically more active in their leisure. Before a prospective study is carried out four conditions need to be met:

(1) A suitable population with 10,000 men or so in early middle age.

(2) A reproducible and valid method for identifying men according to their activity.

(3) A wide range in the study population from the active to the inactive, and sufficient numbers of habitually active and inactive men.

(4) Because large numbers of subjects are involved, data collection should be simple and inexpensive.

The Social Medicine Research Unit has been conducting a series of inquiries with a sample of male executive-class civil servants aged 40-54 years ("executive" is the title used for the grade intermediate between clerical and administrative classes). We view these inquiries as pilots to the prospective study outlined above. The executive-class is in many respects an appropriate population for this study. There are large numbers of men in the age group 40-54; they tend to be drawn from a similar social background; occupational security is high and turnover low; their work is sedentary with few and definable exceptions; uniform records about their health and illness are maintained by the Treasury Medical Service; they are accessible for study, and we know them to be interested, co-operative, articulate, methodical, and time-conscious.

\section{METHOD}

Two types of data can be obtained by questionnaire or interview for measuring habitual levels of leisure activity:

(I) Data on Behaviour.-The subject is asked to report facts about things he had done, and the researcher attempts to estimate from such data the exercise levels involved. 


\section{S. YASIN, M. R. ALDERSON, J. W. MARR, D. C. PATTISON, AND J. N. MORRIS}

(2) Self-Assessment.-The subject is asked to express an opinion about his level of activity in general, or with respect to specific pursuits. The hope here is that the individual's self-opinion will be valid. Hammond (1964a, b), using such a technique, has observed higher age-standardized death rates from all causes in men answering "None" to the question "How much exercise do you get (work or play)?" than in those answering "Slight", "Moderate", or "Heavy".

\section{Procedure}

117 subjects, male executive-grade officers aged $40-54$, in jobs previously ascertained to be sedentary were seen four times-once every 3 or 4 monthsduring the period March, 1964, to May, 1965, and were asked how they spent their leisure time for 2 consecutive days. The subjects were selected at random from the official nominal rolls of five government offices doing sedentary work, and the 117 represent a 95 per cent. co-operation rate of those approached. We interviewed on Mondays and Tuesdays: on Mondays we asked about the previous Friday and Saturday, and on Tuesdays we asked about the previous Sunday and Monday. Thus, after four interviews we had a record for each subject describing 4 weekdays (normally working days) and 4 weekend days (normally non-working days).

We interviewed the subjects in private at their offices during working hours, appointments usually being made 10 days in advance. Before the first interview the men were sent a personal letter of invitation; which told them the interview would concern their "leisure and health". Many of the subjects correctly expected that subsequent interviews would again deal with the reporting and writing up of their recent activities. Throughout the survey period we also interviewed a large number of additional executive-grade officers, drawn from the same nominal rolls, on one occasion only; and from them we collected information about one weekday and one weekend day. The mean and distribution of responses in each period for men interviewed for the first time were similar to those for men being reinterviewed, which suggests that re-interviewing did not bias the results.

The interviewer asked each subject to recall and describe every "activity" during the day in question. Each activity lasting 5 minutes or more, as recalled by the subject, was recorded chronologically in writing at the time by the interviewer, using short descriptive phrases and noting the approximate time (to the nearest 5 minutes) that the activity began and lasted. An excerpt from a Recall Record is given in
Table I. The interviewer checked the times and probed where there was a discrepancy between the clock-time and the reported duration of consecutive activities. The entire day was reconstructed from the time the subject rose in the morning until he retired for the night. We told the subjects that they need not report anything which normally they would not discuss with other people. We did not discuss with them what they did at their place of work; they provided us only with time of arrival and departure and description of activities in the lunch break. "Leisure", according to our definition, includes all activities except occupational duties performed at the place of employment. An experienced interviewer can usually obtain a complete recall record of 2 days' activity in about one hour.

\section{TABLE I}

\begin{tabular}{|c|c|c|}
\hline Time & Details of Respondent's Activity & Minutes' Duration \\
\hline $\begin{array}{l}7.55 \text { a.m. } \\
8.15 \text { a.m. } \\
8.45 \text { a.m. } \\
9.30 \text { a.m. }\end{array}$ & $\begin{array}{l}\text { Made breakfast } \\
\text { Had breakfast } \\
\text { Reading paper } \\
\text { Setting and lighting fire (coal at }\end{array}$ & $\begin{array}{l}20 \\
30 \\
45\end{array}$ \\
\hline $\begin{array}{l}9.40 \text { a.m. } \\
10.00 \text { a.m. } \\
10.15 \text { a.m. }\end{array}$ & $\begin{array}{l}\text { Washing, shaving, dressing } \\
\text { Went shopping, driving car } \\
\text { Shopping, walking around, etc. }\end{array}$ & $\begin{array}{l}10 \\
20 \\
15 \\
45\end{array}$ \\
\hline
\end{tabular}

We also collected a considerable amount of information on civil status, family structure, residence, etc.

\section{The ACtivity Score-Behaviour}

We postulated that a man's description in this kind of detail of the tasks he performed represented usefully "hard" information. A system was next developed to convert the recall records into a score that would reflect the overall activity of each individual and permit grouping and comparison of the men. Each task was "quantitated" by allotting it to one of five levels of activity. This scale was based on published measurements of the ranges and means of oxygen consumption for different activities; the extensive review by Passmore and Durnin (1955) provided the major framework for the classification. Additional information was obtained from Edholm (1956); Edholm, Fletcher, Widdowson, and McCance (1955); Garry, Passmore, Warnock, and Durnin N (1955); Durnin (1957); Assmussen and Poulsen 으 (1963); Covell, el Din, and Passmore (1965); Durnin 6 and Passmore (1967). When no published findings of $\frac{C}{\Phi}$ oxygen consumption could be found for a particular $\stackrel{\oplus}{+}$ task, we fitted it into the scale of activities at what 7 was considered the most appropriate place. The 
activities were next grouped into five fairly coarse divisions primarily for coding. To apply figures for calorie expenditure from experimental results to each specific activity would also have suggested that the scoring system is more accurate than the quality of the data warrants.

A few examples of tasks in the five "levels" of activity are shown in Table II. From one to five points are allotted for each 5 minutes of reported activity: 5 minutes reading $=1$ point, 5 minutes walking $=3$ points, and 5 minutes swimming $=5$ points. Thus for any hour of "waking" activity an individual can score a minimum of 12 and a maximum of 60 points. No attempt was made to obtain the individual's subjective impression of the intensity with which he performed any particular task.

The time spent by these men at the office, apart from the lunch break, was uniformly coded as "sitting", Level A.

TABLE II

OUTLINE OF SCORING SYSTEM USED TO CONVERT RECALL RECORD OF ACTIVITY INTO POINTS

\begin{tabular}{l|c|l}
\hline $\begin{array}{c}\text { Activity } \\
\text { Levels }\end{array}$ & $\begin{array}{c}\text { Points per } \\
5 \text { Minutes }\end{array}$ & \multicolumn{1}{|c}{ Examples } \\
\hline A. Sedentary & 1 & $\begin{array}{l}\text { Reading, Watching T.V., Eating, Sitting } \\
\text { in car, Working with papers (Just being } \\
\text { awake) }\end{array}$ \\
\hline B. Light & 2 & $\begin{array}{l}\text { Personal toilet, Driving car, Preparing } \\
\text { food }\end{array}$ \\
\hline C. Moderate & 3 & $\begin{array}{l}\text { Walking, Shopping, Making and lighting } \\
\text { fire, Hoeing garden }\end{array}$ \\
\hline D. Strenuous & 4 & Decorating, Digging in garden \\
\hline E. Sport & 5 & Swimming, Tennis \\
\hline
\end{tabular}

Individual Daily Activity Score $=$ sum of all points accumulated on any one day.

Two coders independently coded the recall records; the results were then checked and errors corrected. The points scored throughout the time an individual had been awake were added to give an "activity score"; this is accumulated, as a minimum, at the rate of one point per 5 minutes. Any increase over this basal figure is due to leisure activity in excess of sitting.

In addition to these questions on behaviour, we also asked the men a wide range of self-assessment questions, in which they classified themselves as to their present and past activity, in general and in the specific fields of walking, gardening, and sport. Structured questions were used, in reply to which the respondent was required to grade himself as very active / fairly active / average / fairly inactive / very inactive. Each field was explored for habitual activity over the past 10 years, 5 years, 1 year, and 3 months. The men were also asked about the frequency, regularity, and duration of each activity.

\section{ACTIVITY SCORES}

\section{RESULTS}

Table III shows the range and the mean of the daily activity scores derived from the sample of men, grouped arithmetically into "inactive", "middle", and "active" thirds. There was a wide range of activity scores among these civil servants: the lowest mean daily score for an individual was a little over 200 points, the highest close to 400 . When the records of the men with the six lowest and six highest scores are examined, the major difference in the weekend day activities is the time spent in decorating or strenuous gardening. The six least active men averaged only a quarter of an hour, whilst the six most active men were engaged at such tasks for an average of over $3 \frac{1}{2}$ hours per weekend day. There is a difference of nearly 80 points per day between the means of the active and inactive groups; this is equivalent to over 3 hours a day of walking by the active while the inactive were sitting. Moreover, the difference between the limiting cases for these two groups is 31 points-i.e. the least active subject in the active group (312 points) does the equivalent of an additional hour and a quarter of walking per day compared with the most active subject of the inactive group (218 points). This suggests that it is possible to identify two substantial groups whose activity differs considerably.

TABLE III

RANGES AND MEANS OF DAILY ACTIVITY SCORES (BASED ON 8-DAY RECORDS) FOR SAMPLE OF MEN SEPARATED INTO THREE GROUPS

\begin{tabular}{l|c|c|c}
\hline \multirow{2}{*}{ Activity Group } & Number of Men & \multicolumn{2}{|c}{ Activity Score } \\
\cline { 2 - 4 } & & Range & Mean \\
\hline Inactive & 39 & $217-281$ & 262 \\
Middle & 39 & $282-311$ & 297 \\
Active & 39 & $312-399$ & 341 \\
\hline \multicolumn{1}{c|}{ Total } & 117 & $217-399$ & 300 \\
\hline
\end{tabular}

There were small differences in the mean score for the five government offices, which were not statistically significant. The scores were significantly lower during the third of the four interviewing periods, that is for records collected from October to the following January. Hindsight suggests that this is the time of year when leisure activity will be at its lowest.

Though there was a longer recall time from Friday (activity) to Monday (interview) than from Monday (activity) to Tuesday (interview), there is no evidence that the scores for either Friday or Monday activities were consistently high or low. The time lapse between Saturday or Sunday and interview is the same; there is, however, a consistently higher score on each of the Saturdays compared with the relevant 
Sunday, the difference being significant in three out of the four periods. The interviewers could not be allocated at random, but there was no evidence that any obtained records with consistently high or low scores. As said, all the respondents were aged 40-54; there was no tendency for scores to decrease with increasing age within this range. These facts are reassuring. They suggest that the range of activity scores found is not the result of some confounding factor-such as place of work or individual interviewer-but reflects actual differences between individuals.

Table IV shows the mean times spent by the men at various activities for the first weekend day. The varying time spent by individuals at household chores, walking, gardening, and "Do it Yourself" projects is responsible for almost all the range in activity scores.

TABLE IV

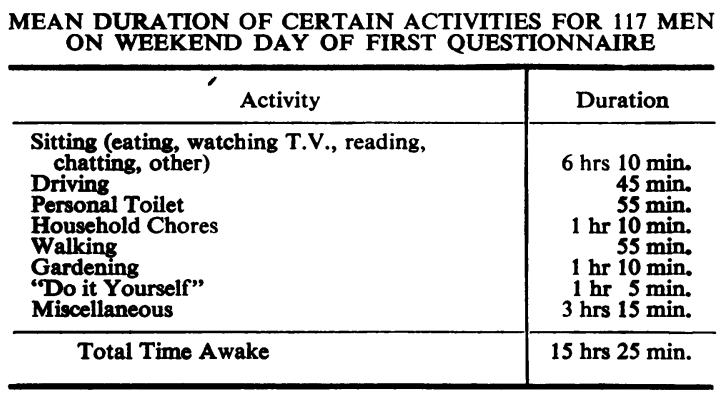

Stability of Activity Scores.-The subjects were originally classified on their total 8-day score. The distribution of the scores was normal, with a slight positive skew; it may be that the active subjects are distinguished from inactive by one or a few unusually strenuous (or sedentary) days out of the eight. There is a correlation of about +0.6 between the scores on weekend days (i.e. a Saturday or Sunday on any of the four interviews) and the total 8-day score. There is also a correlation of +0.55 between total of 4 work days activity scores and total of 4 weekend days. Table $\mathrm{V}$ shows the amount of misclassification that occurs when the subjects are grouped on the score for a single weekend day compared with their total score for the 8 days. (The weekend day reported in the first interview is quoted, although each of the four interviews yielded comparable results.) About a third of the active or inactive subjects as classified by total 8-day score change their category. Moreover, only three of the 117 subjects are grossly so misclassified, "actives" becoming "inactives" or vice versa.
TABLE V

COMPARISON OF GROUPING OF MEN BY WEEKEND DAY OF FIRST QUESTIONNAIRE AND BY 8-DAY ACTIVITY

\begin{tabular}{c|ccc|c}
\hline \multirow{2}{*}{$\begin{array}{c}\text { GrouprNG: } \\
\text { By 8-Day Activity } \\
\text { Score }\end{array}$} & \multicolumn{4}{|c}{$\begin{array}{c}\text { Grouping: } \\
\text { Weekend Dy Activity Score }\end{array}$} \\
\cline { 2 - 5 } & Inactive & Middle & Active & Total \\
\hline Inactive & 27 & 11 & 1 & 39 \\
Middle & 10 & 17 & 12 & 39 \\
Active & 2 & 11 & 26 & 39 \\
\hline Total & 39 & 39 & 39 & 117 \\
\hline
\end{tabular}

Self-Assessment

The self-assessment items, which were collected at $\stackrel{+}{+}$ each of the four interviews, gave results that were $\vec{F}$ highly reproducible. Correlations of up to +0.8 were obtained for two successive administrations of the same question. "How physically active have you been in the past 3 months?" was asked at each of the four interviews. The answers to this question were combined and correlated at +0.39 with the 8-day activity score. The other self-assessment items gaß $\overrightarrow{0}$ insignificant correlations.

\section{VALIDATION}

The Activity Score and the Self-Assessment Scores were reproducible, but only one Self-Assessment gave a significant correlation with the Activity Score. It is possible that the subjects might be reporting what they thought we wanted to hear. We had to try, therefore, to determine whether either method really did measure habitual exercise levels.

Direct observation of subjects for such a purpose is impractical, and physical fitness tests are not an accurate index of habitual moderate activity levels (Assmussen and Poulsen, 1963). We decided to attempt an indirect "biological" validation. Physiologically, there is usually an equilibrium between a man's calorie intake and expenditure. If the men with 윽 high activity scores also had a high calorie intake and $\frac{D}{2}$ the inactive men a low intake, it would suggest that they were being accurately classified. It is also reason- N able to expect the more active men to be thinner.

We, therefore, asked the subjects in Office IV to $N$ participate in a weighed diet survey for one week. This was carried out by J.W.M. (dietitian). The technique adopted is an accepted one for estimating $\odot$ intake (Garry and others, 1955; Thomson, 1958; Marr, Heady, and Morris, 1959) and has been $\stackrel{\circ}{+}$ described in detail by Marr (1965). Of the 37 men in $\frac{T}{\circ}$ that office, 32 co-operated usefully. D.C.P. examined 
the men and, among other things, measured skinfold thickness at three sites (triceps, subscapular, and supra-iliac) on the right side of the body using a Harpenden calliper (Edwards, Hammond, Healy, Tanner, and Whitehouse, 1955). Neither the dietitian nor the physician knew beforehand what were the activity levels of the subjects as derived from the interview.

Table VI indicates the calorie intake and skinfold thickness of the men in this subsample grouped by (a) Activity Score and (b) Self-assessment. Those shown as "active" on the 8-day activity record have a higher calorie intake per $\mathrm{kg}$. body weight than the inactive group (amounting to 150 calories daily per man on average) and thinner skinfolds. The correlation between individual activity scores and calorie intakes was +0.27 (not significant at the 5 per cent. confidence level); that between skinfold measurements and activity scores was -0.31 (significant at the 5 per cent. level). The activity score can also be weighted for the fact that there are usually 5 working days and 2 weekend days in the week. This makes a further slight improvement in the association between activity score and calorie intake.

\section{TABLE VI}

MEAN CALORIE INTAKE AND MEAN SKINFOLD THICKNESS FOR SAMPLE OF 32 MEN GROUPED BY THEIR SCORE FROM:

(A) 8-DAY ACTIVITY RECORD

(B) RESPONSES TO SELF-ASSESSMENT QUESTION "HOW PHYSICALLY ACTIVE HAVE YOU BEEN IN THE PAST 3 MONTHS?" REPEATED AT EACH OF FOUR INTERVIEWS

\begin{tabular}{|c|c|c|c|c|}
\hline \multirow{2}{*}{$\begin{array}{c}\text { Men } \\
\text { grouped on } \\
\text { Score from }\end{array}$} & \multirow{2}{*}{ Mean Values } & \multicolumn{3}{|c|}{ Group of Men } \\
\hline & & Inactive & Middle & Active \\
\hline \multirow{3}{*}{$\begin{array}{l}\text { 8-Day } \\
\text { Activity } \\
\text { Record* }\end{array}$} & $\begin{array}{l}\text { Daily Calories/kg. Body } \\
\text { Weight }\end{array}$ & $36 \cdot 9$ & $40 \cdot 9$ & $41 \cdot 9$ \\
\hline & $\begin{array}{l}\text { Three Skinfolds Thickness } \\
\text { (mm.) } \dagger\end{array}$ & $40 \cdot 9$ & $32 \cdot 2$ & $30 \cdot 9$ \\
\hline & Number of Men & 11 & 10 & 11 \\
\hline \multirow{3}{*}{$\begin{array}{l}\text { Self- } \\
\text { Assessment } \\
\text { Item }\end{array}$} & $\begin{array}{l}\text { Daily Calories/kg. Body } \\
\text { Weight }\end{array}$ & $38 \cdot 4$ & $39 \cdot 5$ & $42 \cdot 4$ \\
\hline & $\begin{array}{l}\text { Three Skinfolds Thickness } \\
\text { (mm.)† }\end{array}$ & $41 \cdot 9$ & $32 \cdot 9$ & $29 \cdot 2$ \\
\hline & Number of Men & 10 & 14 & 8 \\
\hline
\end{tabular}

- Adjustment for Body Weight

The activity score takes no account of an individual's weight; we merely use it to assess whether one man is "on the go" more than another. For the purpose of the validation study, we are however comparing an individual's CALORE intake with his energy expenditureas represented by his activity score; the activity score has therefore to

be corrected for body weight. This has been done using the formula: Expenditure $=$ Raw Activity Score $\times \mathbf{W t}^{\circ \cdot 73}$

This is based on the formula quoted by the United Nations Food and Agricultural Organisation (1950):

Calorie needs $=a \times \mathrm{Wt}^{\circ} \cdot 73$ (where $a=$ constant)

This correction resulted in three of the 32 men changing their group and did not affect the pattern. The calorie intake and corrected score were then compared per $\mathrm{kg}$. body weight.

t Sum of triceps, subscapular, and supra-iliac measurements on right side.
The answers to the self-assessment questions were arbitrarily allotted from 0 to 4 points for the five possible answers "very inactive" to "very active". A score has been obtained by adding the points from the answer at each of the four interviews to the question "How physically active have you been in the past 3 months?". This score was used to divide the men into three groups, as nearly equal in size as possible. Table VI shows that the men who considered themselves "Most Active" had the highest calorie intake per $\mathrm{kg}$. body weight and were also the thinnest.

\section{Discussion}

The results of this pilot inquiry suggest that male executive-class civil servants aged 40-54 are a suitable population for assessing in a prospective study the relation between leisure activity and coronary heart disease. Official approval has readily been given to these pilot studies and the individual men, who are available in adequate numbers, have proved most co-operative. The recall record has been relatively easy to obtain from a structured interview, and the data can be coded and converted into an "activity score". The results obtained at any one interview are reproducible and an individual's score is unaffected by place of work, exact age, or identity of interviewer, and is little affected by season.

One problem with data collected in this way is their validation. Using our method we did not expect a high correlation with calorie intake; in fact we hoped to reach $+0 \cdot 4$. The physiological equilibrium involved is subject to both long-term and short-term imbalance. Even in concurrent measures of energy expenditure and consumption, a correlation of only about +0.70 is obtained (Durnin and Brockway, 1959) and our measures were not concurrent. The 8-day activity records were collected in four interviews spread over 12 to 15 months and the dietary record was based on one period of 7 continuous days. Work in this Unit had obtained a correlation coefficient of only +0.73 between two measures of calorie intake for men who had had a week's weighed diet survey at intervals ranging from 3 months to one year (Morris, Marr, Heady, Mills, and Pilkington, 1963). These various factors would reduce the correlation we could expect between physical activity and calorie intake. It is, therefore, encouraging that calorie intakes and activity scores for this small group were related and that the active men were thinner.

The low correlations between the self-assessment and the activity scores may be due either to the recall record gauging current activity whilst the self-assessment reflects long-term habitual patterns of activity, 
or to inaccuracy in one of the methods. However, one item was highly reproducible and "validated" moderately well. We conclude from this that selfassessments do also reflect a man's activity; further work has to be done with refining the discriminatory power of such questions, and we are currently exploring the use of a "yardstick of activity" against which the men may grade themselves. For a largescale study, it would be necessary to have a question that classified men on a single administration.

The results suggest that these men are fairly stable in their patterns of leisure activity, and that one Saturday or Sunday record will classify a man with sufficient accuracy for our purposes. (The method will provide, in a large-scale prospective study, a 95 per cent. chance of detecting a relationship between leisure activity and subsequent incidence of coronary heart disease, should the anticipated relationship actually exist.) This reduces the amount of data to be collected and the number of contacts required with the subjects. For the assessment of habitual leisure time activity in a study of some 10,000 men, the use of interviewers is impracticable; the cost would be too high and the number of trained interviewers required rules it out. A questionnaire record which the individual completes himself has therefore been administered to a further pilot group of civil servants and the answers are now being analysed. If it proves satisfactory, it will be used in the large-scale prospective study. Wessel, Montoye, and Mitchell (1965) have used this approach, collecting records (a) by interview and (b) from the respondents who completed them in person; they claim that the two methods match.

We have also used alternative methods: recall record and self-assessment. A decision which method is the more suitable for such a large-scale prospective study (or whether the two could be combined) requires further validation on larger numbers, and this is now in progress.

Support of the hypothesis that physical activity in leisure protects against coronary heart disease would provide the basis for campaigns to increase the leisure activity of men in sedentary occupation.

\section{SUMmaRY}

A variety of studies in different countries support the hypothesis that habitual physical activity of occupation protects against coronary (ischaemic) heart disease; it is now important to assess the effect of physical activity in leisure. Before a large-scale prospective study can be carried out, a simple reproducible and valid method of assessing leisuretime activity has to be developed.

(1) Male executive-class civil servants aged 40 to 54 years were given a structured interview to obtain $\stackrel{5}{9}$ a recall record of activities for 2 days before the $\bar{O}$ interview (one a work day, the other a weekend day). A sample of 117 men working in five different offices were interviewed on four occasions and the 8-day records for these men were converted into an individual "activity score".

The mean score for the active third of the men was greater than that of the inactive third by the equivalent of over 3 hours' walking per day. There was no evidence that an individual's score was influenced by his age, the office in which he worked, or the person who interviewed him. Mean scores were slightly lower in the winter.

There was a correlation of about +0.6 between a man's score on any one of the 4 weekend days and 9 his total 8-day score. The results are thus reproducible, and the men reasonably consistent in their behaviour. A single day's record appears to classify a man sufficiently accurately for our purposes.

(2) All the men were also asked a number of $\vec{\bullet}$ self-assessment questions in which they had to grade of their own physical activity on a five-point scale. The answers were highly reproducible. One question relating to general activity over the past 3 months was repeated at each of the four interviews; the score for this item gave a correlation of +0.39 with the 8-day activity score.

In a sample of 32 men at one office, the active third were found to have a higher calorie intake per kg. body weight and thinner skinfolds than the inactive men. This biological validation of the methods suggests that the activity score and selfassessment distinguish men who-actually are physically active from those who are not.

The difference in reported activity between the active and inactive men is conceivably wide enough to be related to health.

We are most grateful for the assistance we have received from the Treasury, the central and local staff of N the four ministries whose men we interviewed (Defence. Inland Revenue, Labour, and Pensions and National Insurance), and the various staff associations concerned. N The participation by the individuals in our samples has been most gratifying: without their very willing co-operation this study could not have proceeded.

We have profited from discussions held with $\mathrm{Dr} J$. A. Heady, Assistant Director, and with many colleagues within and outside this Unit. We are especially indebted 
to $\operatorname{Dr}$ A. N. Oppenheim for advice on questionnaire design, and to Drs J. V. G. A. Durnin, R. Passmore, and A. M. Thomson, whom we consulted about the validation. It is a pleasure to acknowledge the help of Mrs B. Machin and Mrs J. Green in coding the data.

\section{REFERENCES}

Alexsandrow, D. (1962). Cardiol. prat., 13, 96.

Assmussen, E., and Poulsen, E. (1963). Testing and Observation Institute of the Danish National Association for Infantile Paralysis, Communication No. 13.

Breslow, L., and Buell, P. (1960). J. chron. Dis., 11, 421.

Brown, R. G., Davidson, L. A. G., McKeown, T., and Whitfield, A. G. W. (1957). Lancet, 2, 1073.

Brunner, D., and Manelis, G. (1960). Ibid., 2, 1049.

Chapman, J. M., and Massey, F. J. (1964). J. chron. Dis., $17,933$.

Covell, B., el Din, N., and Passmore, R. (1965). Lancet, $1,727$.

Dawber, T. R., Kannel, W. B., and Friedman, G. D. (1966). In "Prevention of Ischemic Heart Disease", ed. W. Raab, p. 254. Thomas, Springfield, Ill.

Durnin, J. V. G. A. (1957). J. Physiol. (Lond.), 136, 34P. — and Brockway, J. M. (1959). Brit. J. Nutr., 13, 41.

- and Passmore, R. (1967). "Energy, Work, and Leisure". Heinemann, London.

Edholm, O. G. (1956). Proc. Nutr. Soc., 15, 80.

- Fletcher, J. G., Widdowson, E. M., and McCance, R. A. (1955). Brit. J. Nutr., 9, 286.

Edward, D. A. W., Hammond, W. H., Healy, M. J. R., Tanner, J. M., and Whitehouse, R. H. (1955). Ibid., 9, 133.

Frank, C. W., Weinblatt, E., Shapiro, S., and Sager, R. V. (1966). J. Amer. med. Ass., 198, 1241.
Garry, R. C., Passmore, R., Warnock, G. M., and Durnin, J. V. G. A. (1955). Spec. Rep. Ser. Med. Res. Coun. (Lond.), No. 289.

Hammond, E. C. (1964 a). Amer. J. publ. Hlth, 54, 11. - (1964 b). J. Nat. Canc. Inst., 32, 1161.

Higgins, I. T. T., Cochrane, A. L., and Thomas, A. J. (1963). Brit. J. prev. soc. Med., 17, 153.

Kahn, H. A. (1963). Amer. J. publ. Hlth, 53, 1058.

Keys, A., Aravanis, C., Blackburn, H. W., van Buchem, F. S. P., Buzina, R., Djordjević, B. S., Dontas, A. S., Fidanza, F., Karvonen, M. J., Kimura, N., Lekos, D., Monti, M., Puddu, V., and Taylor, H. L. (1966). Acta med. scand., Suppl. 460.

Marr, J. W. (1965). Nutrition, 19, 18.

, Heady, J. A., and Morris, J. N. (1959). Proc. Nutr. Soc., 18, xii.

Morris, J. N. (1967). "Uses of Epidemiology", 2nd ed. Livingstone, Edinburgh and London.

- and Crawford, M. D. (1958). Brit. med. J., 2, 1485. , Heady, J. A., Raffle, P. A. B., Roberts, C. G., and Parks, J. W. (1953). Lancet, 2, 1052, 1111.

Marr, J. W., Heady, J. A., Mills, G. L., and Pilkington, T. R. E. (1963). Ibid., 1, 571.

Myasnikov, A. L. (1962). Cardiol. prat., 13, 72.

Passmore, R., and Durnin, J. V. G. A. (1955). Physiol. Rev., 35, 801.

Skinner, J. S., Benson, H., McDonough, J. R., and Hames, C. G. (1966). J. chron. Dis., 19, 773.

Taylor, H. L., Klepetar, E., Keys, A., Parlin, W., Blackburn, H., and Puchner, T. (1962). Amer. J. publ. Hlth, 52, 1697.

Thomson, A. M. (1958). Brit. J. Nutr., 12, 446.

United Nations (1950). "Calorie Requirements". Food and Agriculture Organization Nutrition Study No. 5. Washington.

Wessel, J. A., Montoye, H. J., and Mitchell, H. (1965). Amer. J. publ. Hlth, 55, 1430.

Zukel, W. J., Lewis, R. H., Enterline, P. E., Painter, R. C., Ralston, L. S., Fawcett, R. M., Meredith, A. P. and Peterson, B. (1959). Ibid., 49, 1630. 